\title{
São Rafael: uma barragem, uma nova cidade e as memórias da cidade encantada
}

São Rafael: a dam, a new town and the memories of the enchated town

João Batista Figueredo de Oliveira Doutorando em Ciências Sociais - PPGCS/UFRN jb.figueredo@hotmail.com 
Visitei São Rafael (RN) no ano de 2013, naquele tempo, a torre da Igreja Católica Romana que ficava para fora das águas da grande barragem, já não existia mais, havia ruído pelos embates do tempo; durante anos resistiu e servia de símbolo das memórias da antiga cidade. A barragem foi construída em 1983 - levando o nome de Armando Ribeiro Gonçalves, o seu projeto previu uma dificuldade: a cidade de São Rafael estava no caminho em que as águas passariam. Planejou-se uma nova cidade para aquela população, a retirada dos moradores foi um processo doloroso, muitos narram o retorno de algumas famílias para as casas que as primeiras cheias não submergiram: "alguns moradores voltavam para suas casinhas na esperança de que tudo seria como antes", mas, a cidade se encantou nas profundezas daquele "mar d'água" e de seus corações.

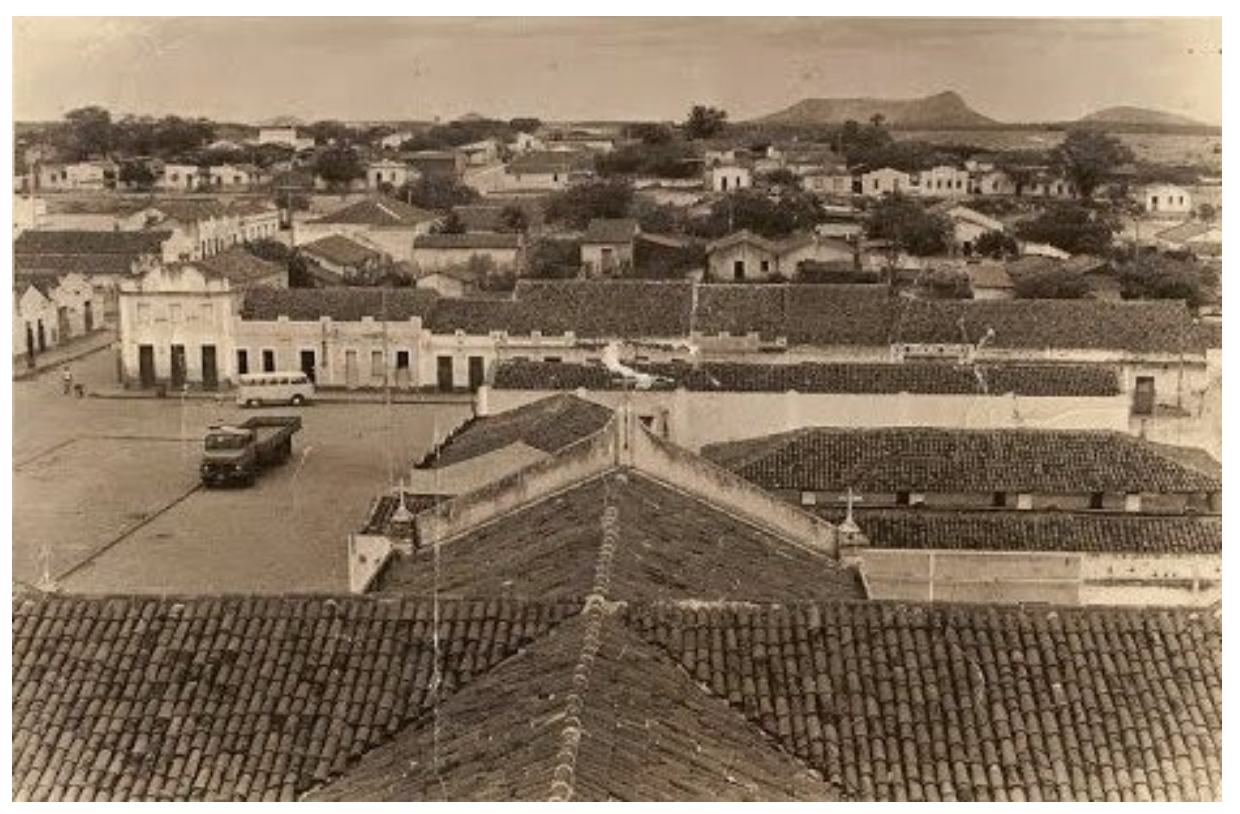

Antiga São Rafael, antes da retirada da população por motivo da construção da Barragem Armando Ribeiro Gonçalves. Partes da população partilha sua tristeza com a destruição do patrimônio cultural e com práticas tradicionais de cultivos de agricultura e pecuária que a mudança não possibilitou a permanência. Foto: Autor desconhecido ${ }^{2}$. 


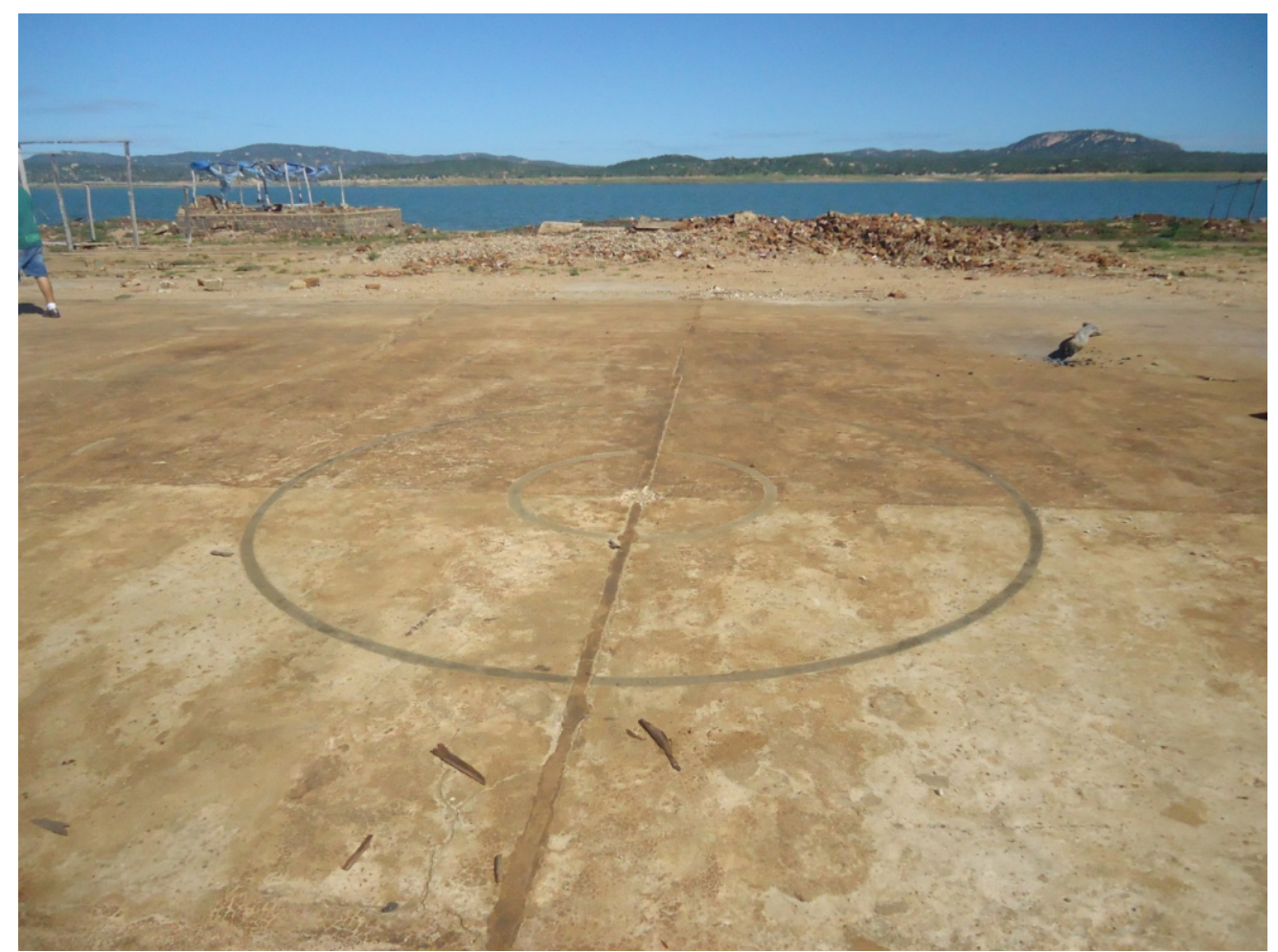

Com a baixa no nível de água da barragem, pode ser observada a antiga quadra de esportes onde ocorriam diversas manifestações esportivas e culturais da antiga cidade. Foto: João Oliveira.

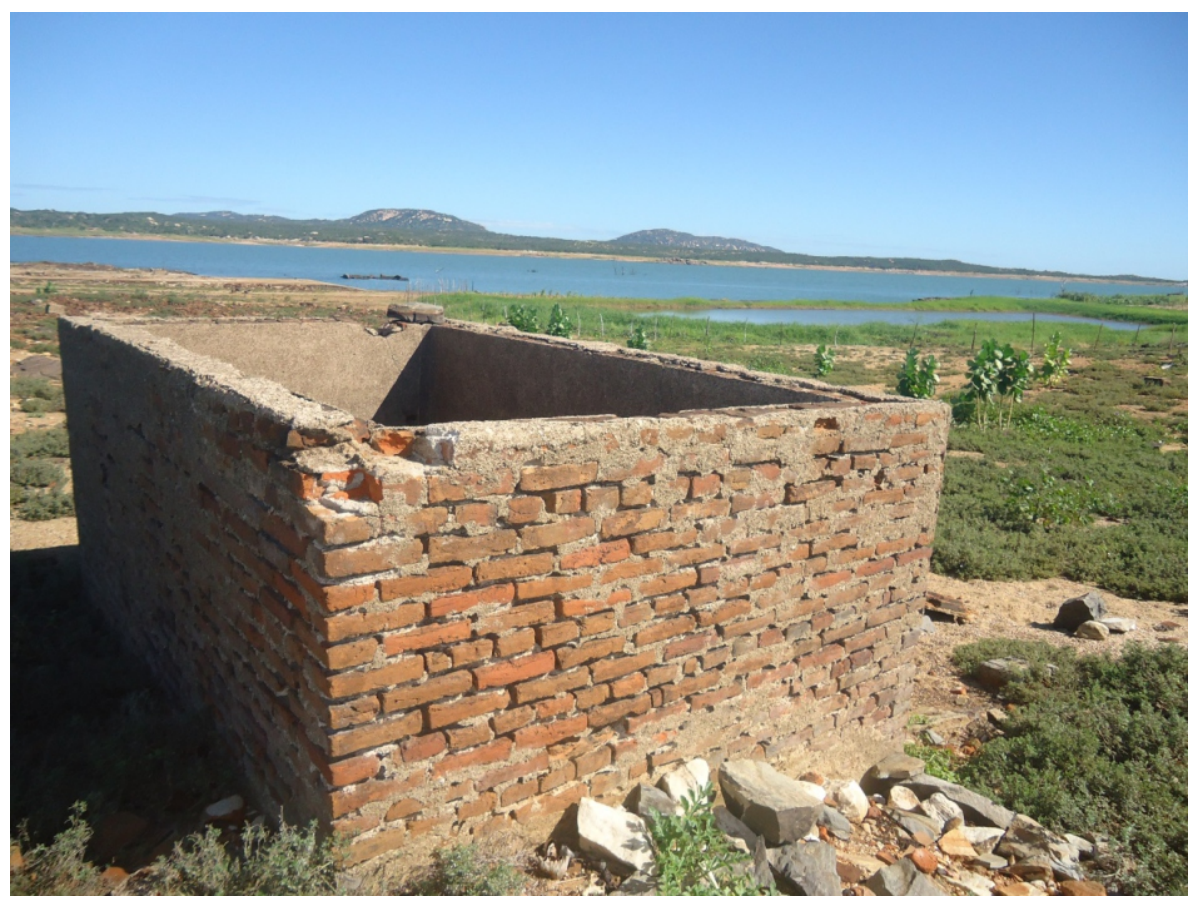

Caixa d'água - uma das únicas estruturas que resistiu as inundações. Foto: João Oliveira. 
São Rafael: uma barragem, uma nova cidade e as memórias da cidade encantada

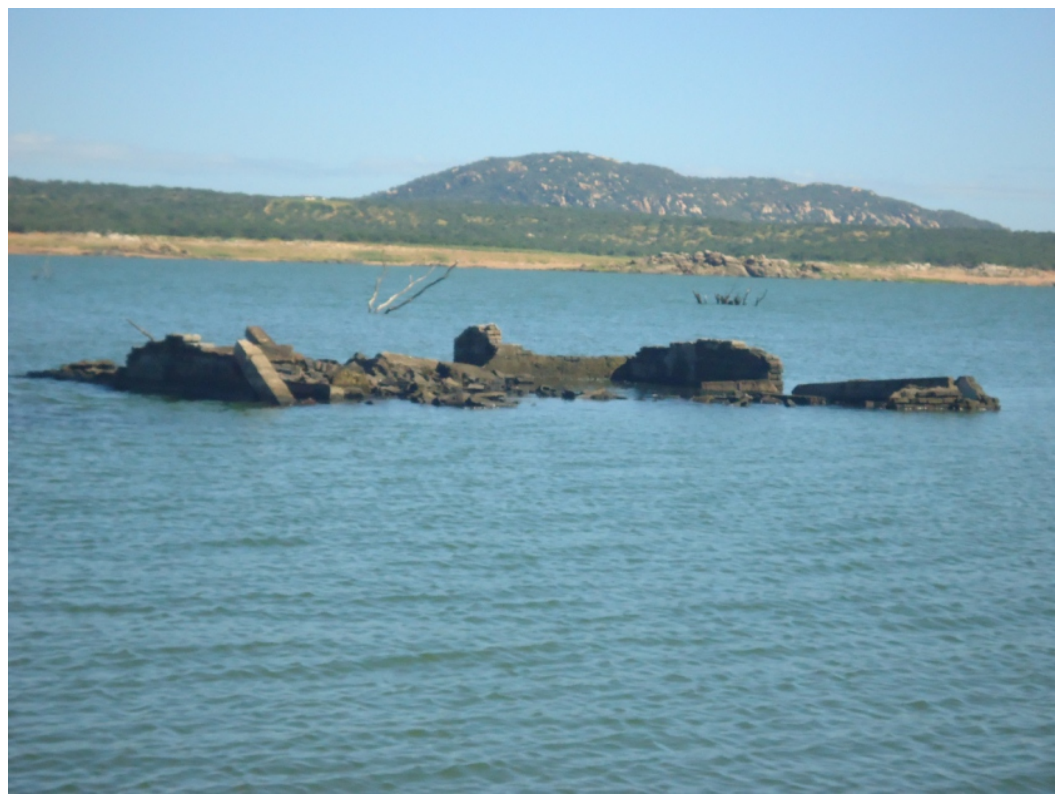

Parte de um dos prédios - Com a baixa no nível de água, desponta as lembranças do passado. Foto: João Oliveira.

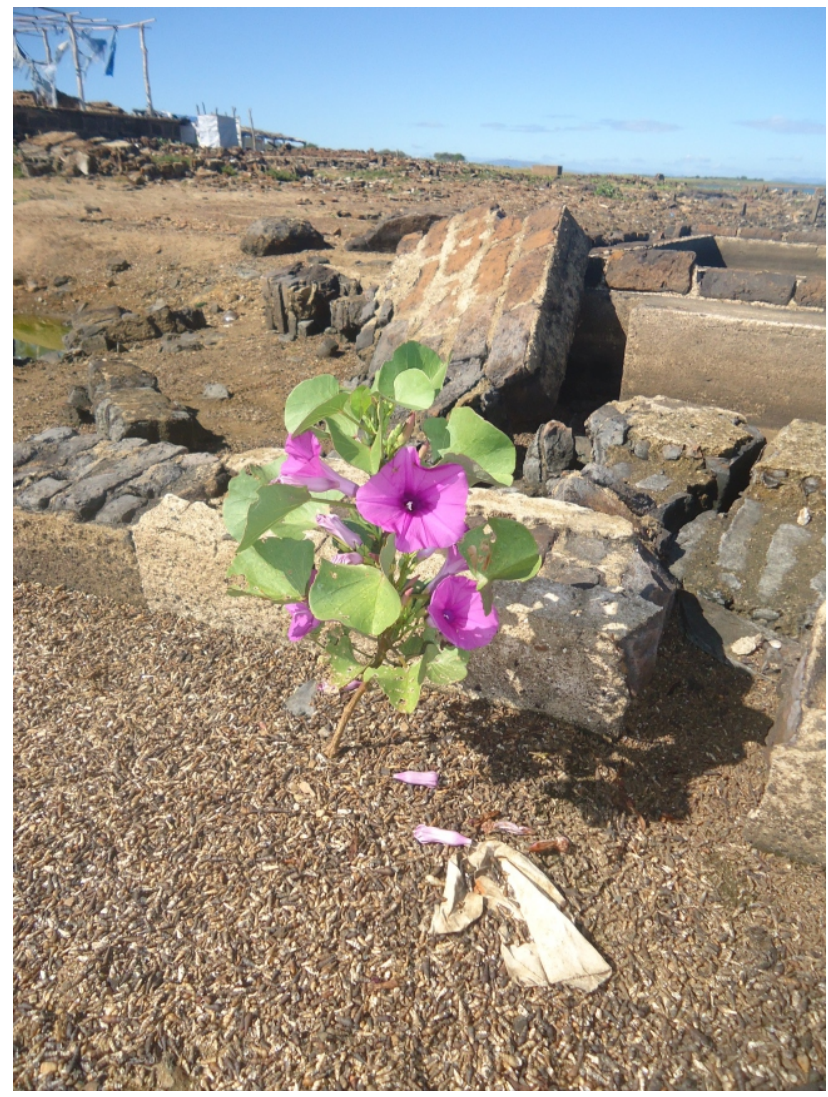

Flores e ruinas - Algumas partes mais elevadas da cidade só ficam em baixo das águas quando as cheias são mais potentes. Foto: João Oliveira. 


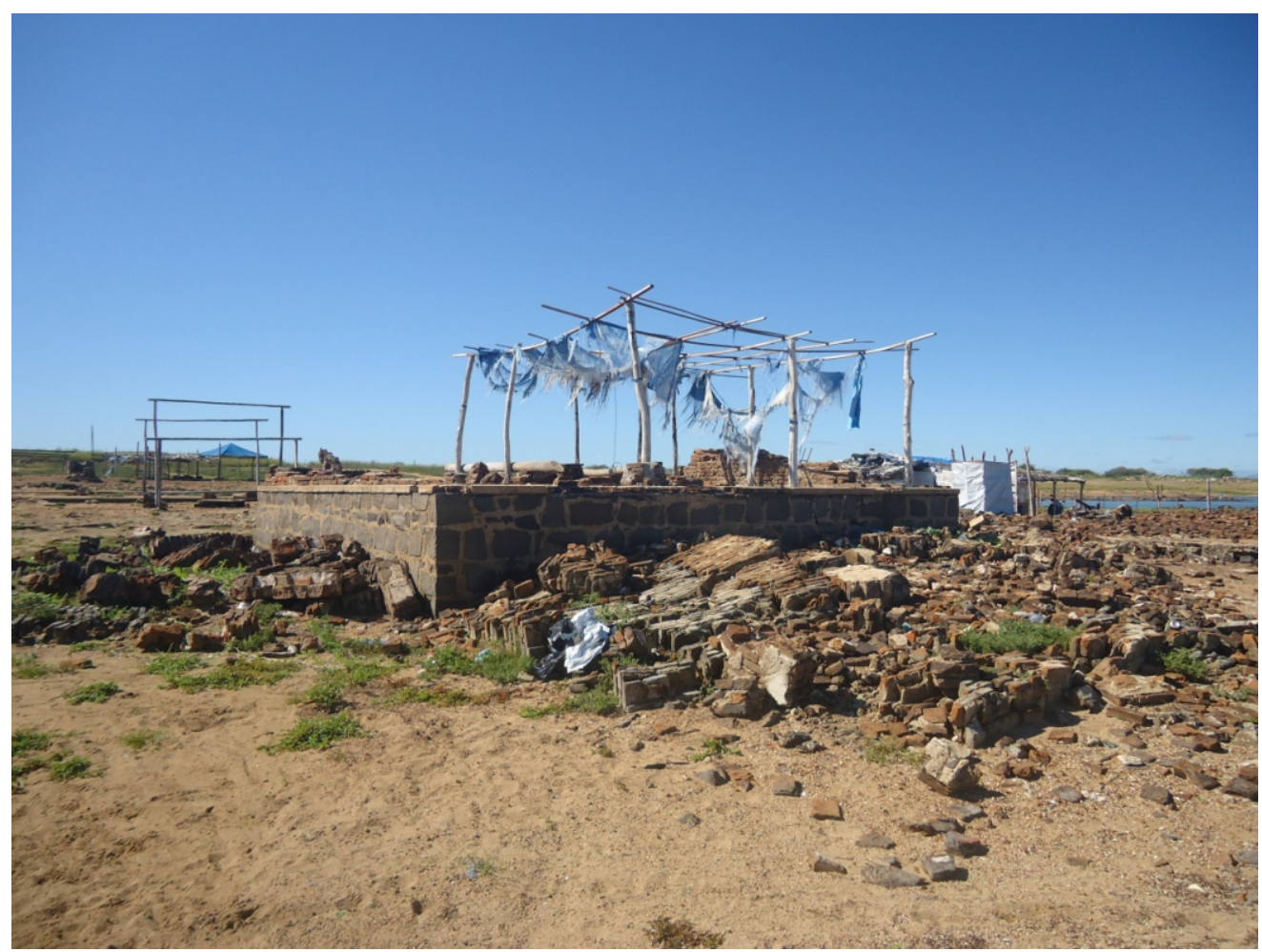

Barraca do pós inundação - construída utilizando uma estrutura que restou de uma das construções da cidade velha. Foto: João Oliveira.

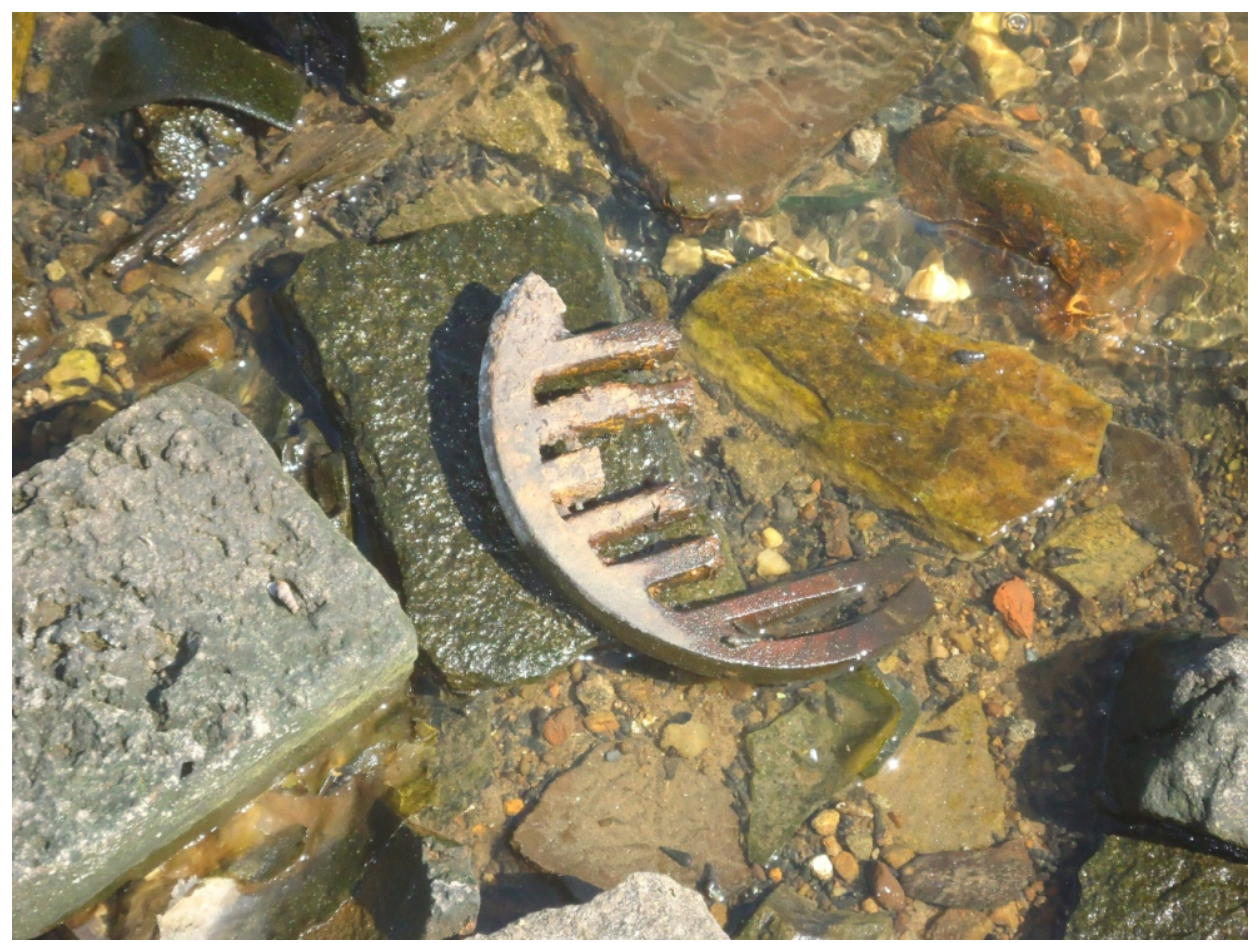

Vestígios - em um passeio, pelas bordas da barragem, é possível encontrar diversos objetos que faziam parte das estruturas das casas. Foto: João Oliveira. 
São Rafael: uma barragem, uma nova cidade e as memórias da cidade encantada

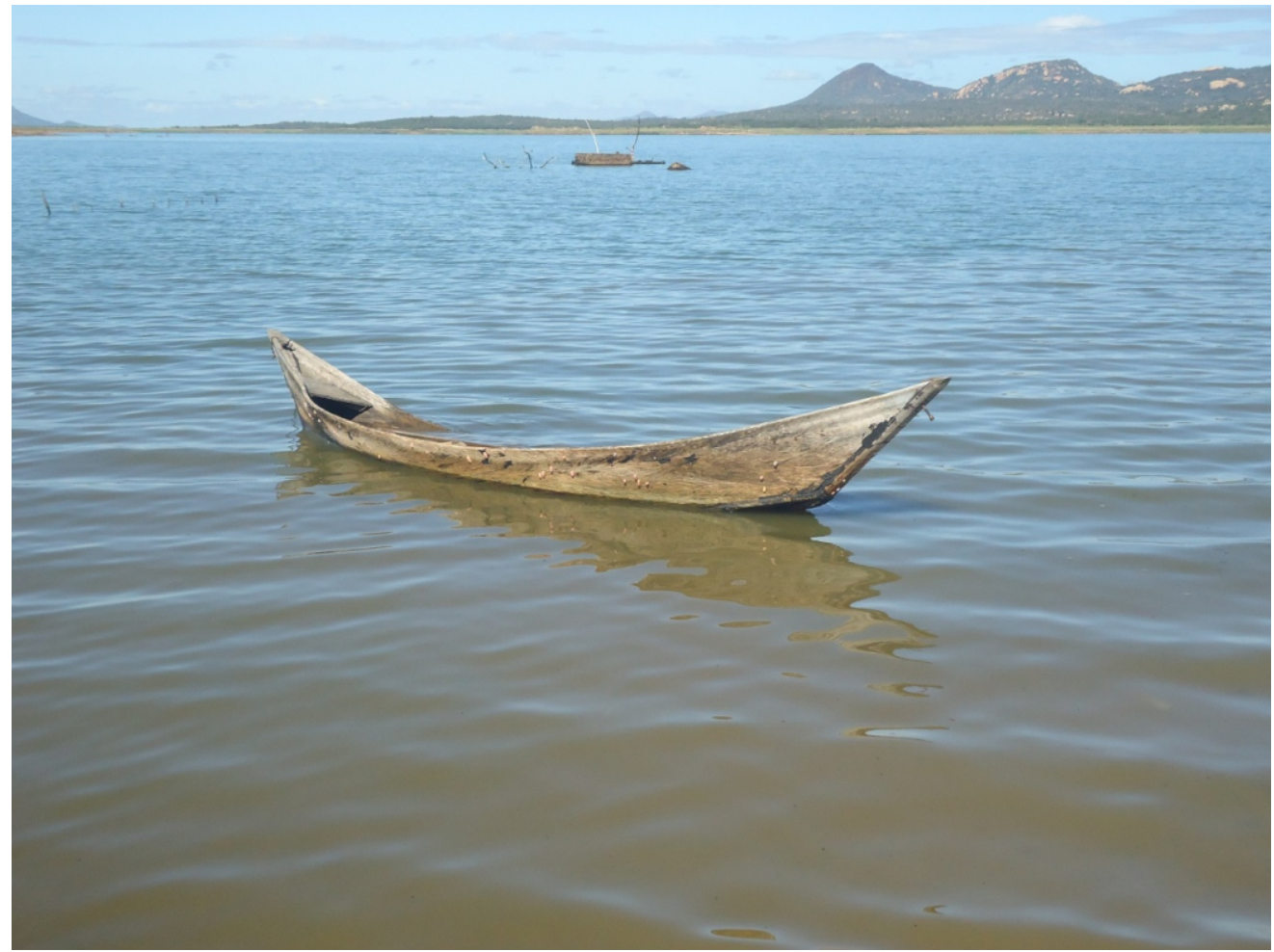

Canoa sobre as águas, resistindo ao tempo, símbolo da pesca e da garra da população de São Rafael. Foto: João Oliveira.

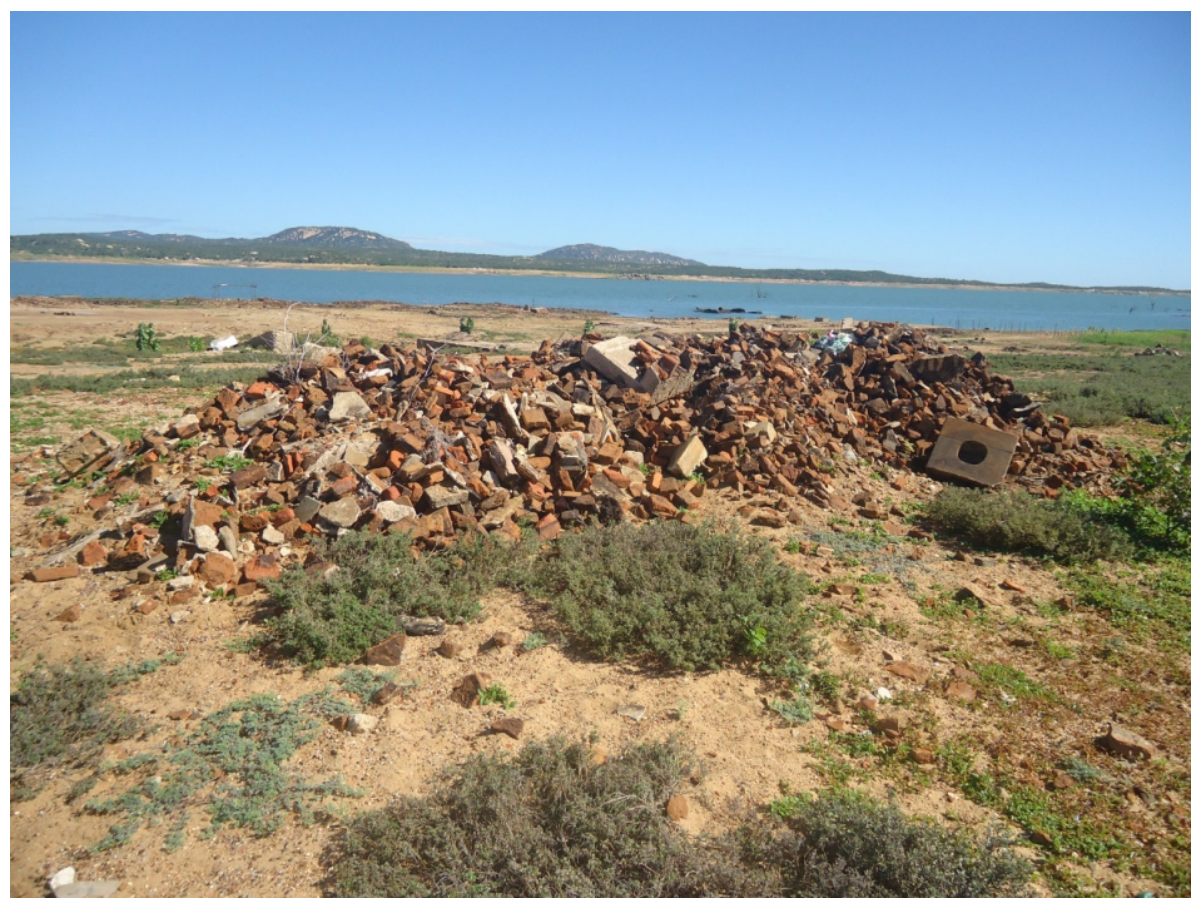

Casa demolida - as recordações dos antigos moradores reaparecem a cada seca. Foto: João Oliveira. 


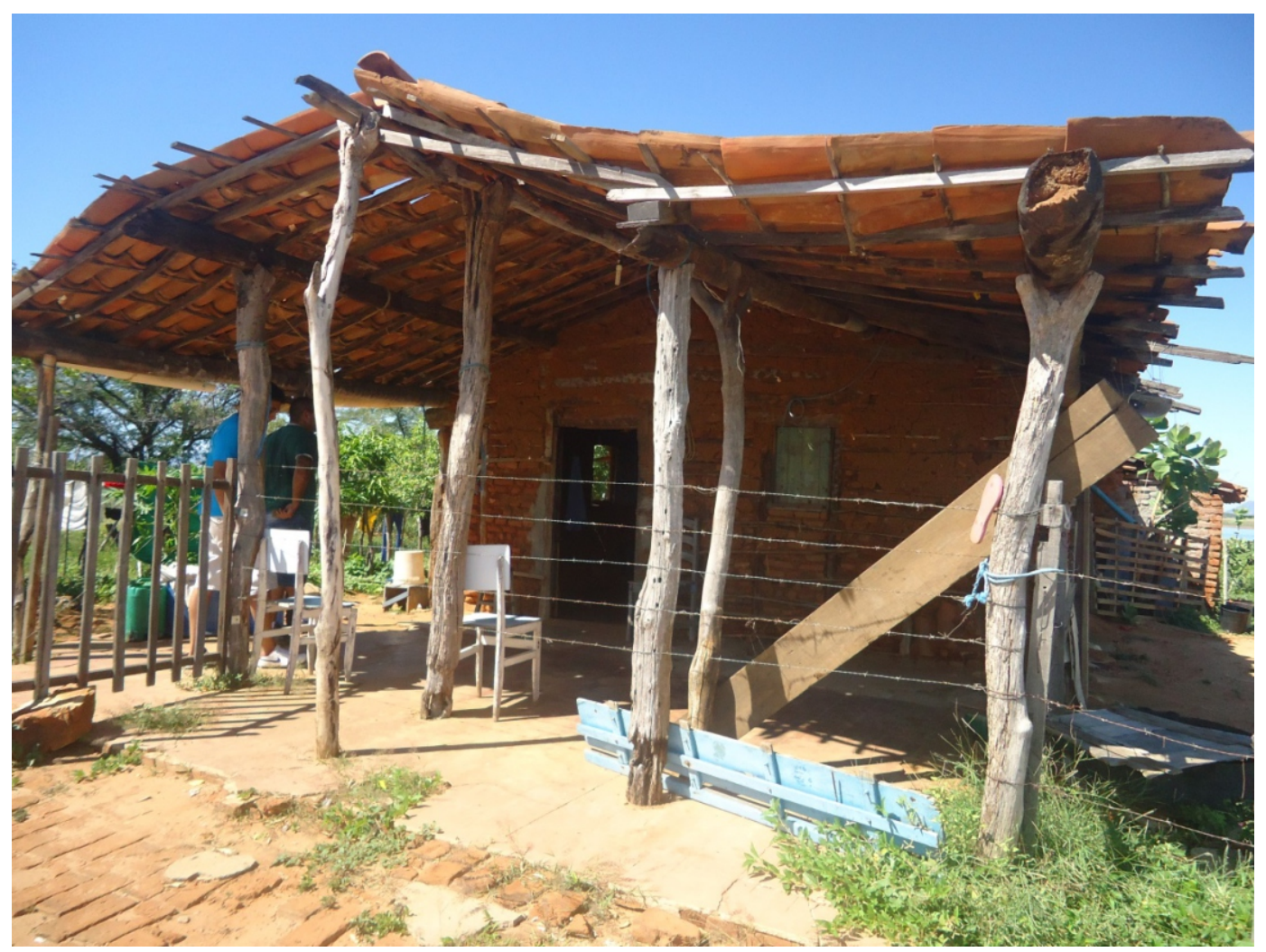

Uma casa (de taipa) de um pescador, uma das únicas, nas proximidades da barragem no espaço perto de onde era a antiga São Rafael. Foto: João Oliveira.

\section{Notas}

1. Trecho da fala de seu José, pescador que vivenciou o processo de mudança da população da antiga cidade para a atual São Rafael.

2. Fonte da fotografia: https://www.youtube.com/watch?v=FJUi6CKmpOA. (Consulta em $22 / 05 / 2016)$ 